\title{
Nesting biology of a female Long-wattled Umbrellabird Cephalopterus penduliger in north-western Ecuador
}

\author{
JORDAN KARUBIAN, GABRIELA CASTAÑEDA, JUAN F. FREILE, \\ RAMIRO T. SALAZAR, TATIANA SANTANDER and THOMAS B. SMITH
}

\begin{abstract}
Summary
Long-wattled Umbrellabirds Cephalopterus penduliger are restricted to the Chocó Biogeographical Region, an area with exceptional levels of avian diversity and endemism. Due to widespread habitat loss and hunting pressure, the species is considered globally Vulnerable and Endangered within Ecuador. Little is known of the species' basic biology. This paper presents data on the first confirmed nest recorded for the species. The nest was found in June 2002 atop a tree fern Cyathea sp. located in secondary forest near Mindo, north-west Ecuador, at 1,600 $\mathrm{m}$ in the subtropical zone of the Andean slope. Data collected during incubation and nestling provisioning suggest that females may be responsible for all parental care. At the nest, the female provided food an average of once per hour, and brought roughly twice as many invertebrate food items as vertebrate or regurgitated food items. A male was never seen at the nest. In addition to presenting data from the nest, we compare Long-wattled Umbrellabirds to congeners and discuss implications for the conservation of this species.
\end{abstract}

\section{Introduction}

The Chocó Biogeographical Region spans 100,000 km² from north-western Colombia into north-western Ecuador, and boasts exceptional levels of endemism in a wide range of taxa including plants, reptiles, amphibians, birds and butterflies (Dodson and Gentry 1991, Dinerstein et al. 1995, Stattersfield et al. 1998, Conservation International 2001). For example, the Chocó supports at least 67 endemic bird species (in addition to a number of distinctive subspecies), the world's highest continental concentration of avian endemism (Salaman 2001). However, there is widespread concern that habitat loss and degradation in the Chocó has caused population declines in many taxa (Dodson and Gentry 1991, Dinerstein et al. 1995, Sierra 1999, Conservation International 2001).

Long-wattled Umbrellabird Cephalopterus penduliger is a Chocó endemic which has suffered a population decline due largely to habitat loss and hunting pressure (Berg 2000, BirdLife International 2000, Jahn and Mena-Valenzuela 2002). Population size is estimated at 2,500-10,000 individuals and the species is considered globally Vulnerable and Endangered within Ecuador (BirdLife International 2000, Jahn and Mena-Valenzuela 2002).

Relatively little is known of the basic biology of Long-wattled Umbrellabirds. The species inhabits interiors and borders of humid and wet forest in the Pacific lowlands, as well as in the foothills and subtropical zones of the west Andean slopes. In Ecuador the species is most numerous in the 
north-western provinces of Esmeraldas and Pichincha (Ridgely and Tudor 1994, Jahn et al. 1999, Berg 2000, Ridgely and Greenfield 2001, Jahn and Mena-Valenzuela 2002). However, its range extends southward in a narrow band along the western foothills of the Andes into the southern El Oro province. Long-wattled Umbrellabirds range in elevation from $80 \mathrm{~m}$ to at least $1,600 \mathrm{~m}$ above sea level. Altitudinal migrations within this range are suspected but unconfirmed (Ridgely and Tudor 1994, Jahn et al. 1999, Berg 2000, Ridgely and Greenfield 2001, O. Jahn pers. comm.). They primarily eat large fruits from trees (e.g. Arecaceae, Lauraceae, Meliaceae and Myristicaceae) but also take smaller fruits, small vertebrates, and invertebrates (Snow 1982, Berg 2000, Ridgely and Greenfield 2001). Although there have been reports of unconfirmed nests (Goodfellow 1902, von Hagen 1938, Berg 2000), a confirmed nest has never been reported for this species and there are no published data on nesting behaviour.

In this paper, we present data on the first confirmed nest recorded for Long-wattled Umbrellabird and discuss the conservation implications of our findings.

\section{Study area and methods}

This study was conducted at Sachatamia Lodge, near Mindo $\left(79^{\circ} 50^{\prime} \mathrm{W}, \mathrm{O}^{\circ} \mathrm{O} \mathrm{I}^{\prime} \mathrm{S}\right)$, Pichincha province, north-west Ecuador. Sachatamia is situated at $1,600 \mathrm{~m}$ elevation, on $\mathrm{km} 78$ of the Calacali-La Independencia road. The lodge reserve comprises 150 ha, and includes areas of primary, regenerating and disturbed forest as well as pasture. Neighbouring land is a mosaic of pastureland and primary and degraded forests.

The forest in which the nest was located had been selectively logged and had regenerated naturally for $c$. 30 years. Cecropiaceae was the dominant tree family. The understorey was fairly dense, and characterized by Cyatheaceae tree ferns and terrestrial aroids. We estimated canopy height in the nest area to average $15 \mathrm{~m}$, canopy coverage $30 \%$, and understorey coverage $60 \%$. This forest area was continuous to the east and south, gradually grading into undisturbed forest, and was bordered by pasture on one side and the road to the other.

We observed the nest from a blind located roughly $25 \mathrm{~m}$ from the nest, between 06 hoo and 10 hoo and from 15 hoo to $18 \mathrm{~h}_{30}(n=450 \mathrm{~min}$ per day) for nine consecutive days from 15 to 23 July 2002. Observations were made with a $20 \times-45 \times$ spotting scope. We recorded each food item the female brought and the relative proportion of time she spent brooding, feeding the chick, and away from the nest. Additionally, we made detailed notes on chick plumage and soft parts coloration, nest site selection, and nest architecture. We also gathered information on incubation by the female, including egg size and coloration, in a less regimented manner. Information on previous use of the habitat was provided by the owners of Sachatamia Lodge, and distances to primary forest were estimated using aerial photographs.

Data were analysed using SAS statistical software (Raleigh, NC). All data are presented as means \pm S.E. unless otherwise stated. 


\section{Results}

\section{Nest site description}

The nest was found on 24 June 2002 by Segundo Quishpe, an employee of Sachatamia Lodge. It was located immediately adjacent to a frequently used (at least once per day) trail that ran parallel to a small creek amd was less than $200 \mathrm{~m}$ from the Sachatamia Lodge, a cleared pasture with cows on it, and the paved highway. The nest was $1.2 \mathrm{~km}$ from undisturbed forest and $1.5 \mathrm{~km}$ from a lek site in primary forest at which males display.

Because this was the first confirmed nest for this species, it received a good deal of publicity after its discovery. Birdwatchers and tourists visited the nest nearly every day after it was discovered, maintaining a distance of about $25 \mathrm{~m}$. Efforts were made by the owners of the lodge to minimize impact of observers but the female was clearly aware of observer presence. While incubating or brooding, for example, she moved to look at observers who came to see the nest. During our observation periods, she often looked in the direction of the blind we had erected. While the female did not show any obvious signs of distress and continued with her nesting behaviour, she probably experienced a mild level of stress due to human presence.

\section{Description of the nest}

The nest was built in the crotch of a tree fern Cyathea sp. with $18 \mathrm{~cm}$ diameter at breast height (dbh). The nest was situated $5 \mathrm{~m}$ above the ground, and was well concealed by the fern fronds. It was an open, bulky cup made of dry sticks roughly $50 \mathrm{~cm}$ in length and $1 \mathrm{~cm}$ in diameter. The cup rim and interior were made of thinner twigs, epiphyte roots, tree fern twigs and mosses. Lodge owners removed two fronds from the fern upon discovery of the nest, during incubation stage, to facilitate observation of the nest.

\section{Clutch size and incubation stage}

The female was well into incubation when the nest was discovered. She had been spotted in the area on a regular basis in the days prior to discovery of the nest. The clutch consisted of one whitish egg with brown speckles at both edges. The egg was observed with a spotting scope and never handled. We estimate that the egg was $5 \mathrm{~cm}$ in length.

One of us (RTS) made extensive but unquantified observations of the nest during female incubation. During the incubation stage, the female left the nest about three times per day, in the morning, midday, and late afternoon. The nest was left unattended for 30-6o min. She usually departed the nest in the same direction (flying downhill parallel to the creek, away from the lodge and toward primary forest located $1.2 \mathrm{~km}$ away) but would return to the nest along one or two general routes perpendicular to the creek. The female was cautious when returning to the nest, and often dropped to the ground and hopped the final few metres toward the nest before flying up to its edge from below. She was never heard to vocalize. 


\section{Nestling description}

The nestling hatched on 11 July 2002. We began our observations four days posthatching, at which time the nestling was covered with bright ochre down, which gradually became duller over the course of a few days. The bill was black, the gape and mouth creamy yellow, and the skin around face and cloaca black. Although we could not hear any nestling vocalizations because of our distance from the nest, we could ascertain with the spotting scope that the nestling began begging actively on 17 July (six days post-hatching), and opened its eyes on 19 July (eight days post-hatching). By 22 July feather sheaths were noted over all the feather tracks, and a small wattle was developing (M. Tellkamp pers. comm.). On 19 July, after being fed, the chick emitted a soft "haam-hamm" call that was barely audible from our position in the blind (recordings available from JFF).

\section{Nestling feeding and brooding stage}

We made detailed observations of parental care at the nest for nine consecutive days of nestling feeding, during which the nestling was 4-12 days post-hatching. Although there was one unconfirmed report of a male in the nest area (S. Salazar pers. comm.), he never approached the nest and all parental care was provided by the female.

The female visited the nest roughly once per hour during our observation period ( $1.06 \pm 0.1$ visits per hour, $n=58$ total visits), though the rate increased sharply in the last two days of observation (Figure 1). All but three female visits were associated with feeding the nestling. As would be expected, the female spent more time away from the nest as the chick grew older (Figure 2).

The female brought a wide variety of vertebrate and invertebrate items for the nestling to eat, and regurgitated unknown food items relatively frequently (Table 1). We identified all non-regurgitated items at least to taxonomic order. Vertebrate items were all amphibians or reptiles, primarily lizards Anolis spp. Invertebrate items consisted of a variety of large insects (Table 1).

The relative proportions of the three classes of food items (vertebrate, invertebrate, and regurgitated items) did not show a clear pattern over the course of the study (Figure 3). However, invertebrate items were brought with greater regularity and were recorded on each day, whereas vertebrate and regurgitated items were brought to the nestling less frequently.

\section{Nest fate}

At 18 hoo on 23 July 2002 the female was seen in the area of the nest. At o7hoo on 24 July, the chick was found dead, hanging from the edge of the nest. The body of the chick was cold but was not noticeably injured, and it appears that the chick died of exposure in the night, during which it had rained heavily. The female was not seen in the area again, despite several attempts to find her. Two weeks later, however, a male and female were seen in the same area.

Although the cause of the failure of the nest is uncertain (none of the authors were present at that time), it is possible that the female was startled by a series of flash photographs taken at the nest at approximately 18 h 15 on 23 July 2002 


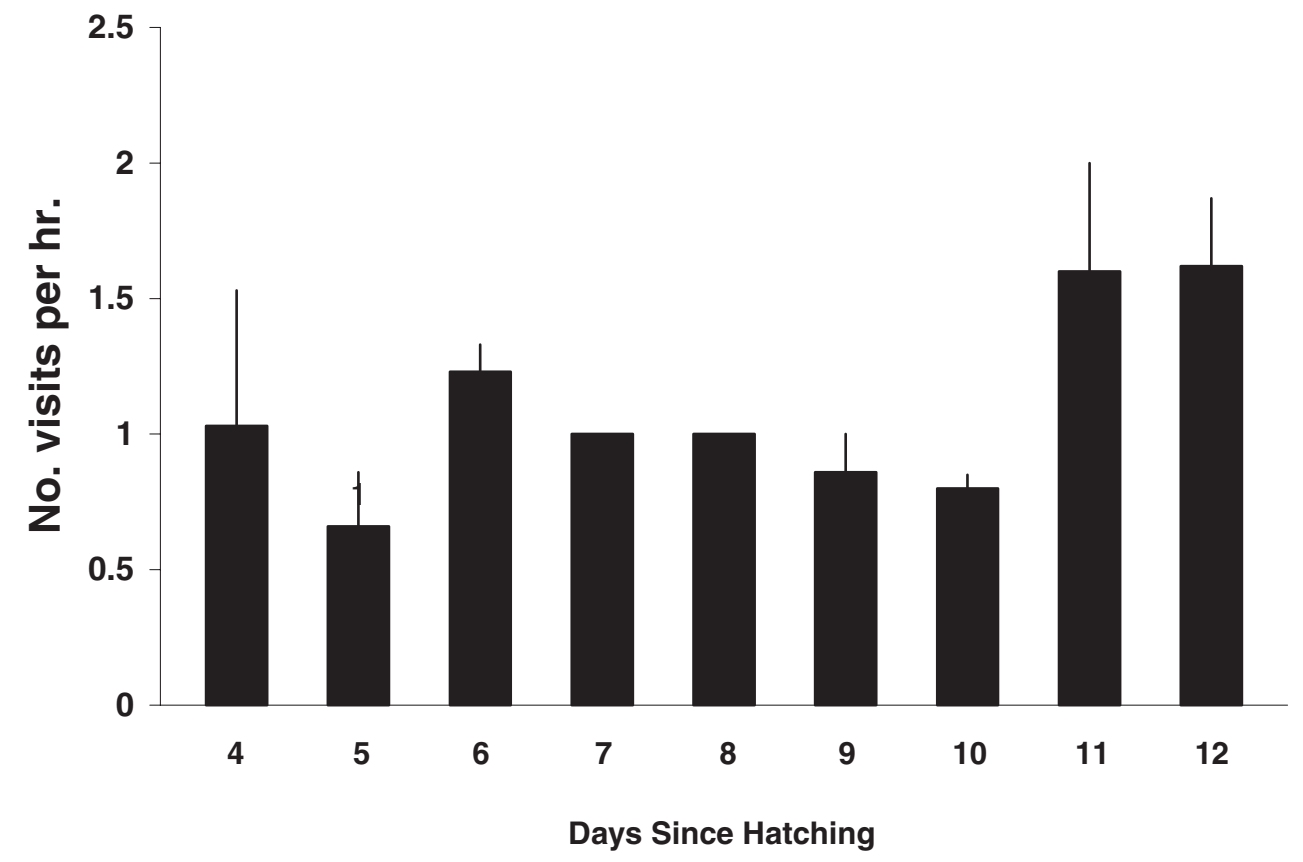

Figure 1. Feeding rate of a single nestling by a female Long-wattled Umbrellabird. Mean number of visits per hour \pm S.E. are shown.

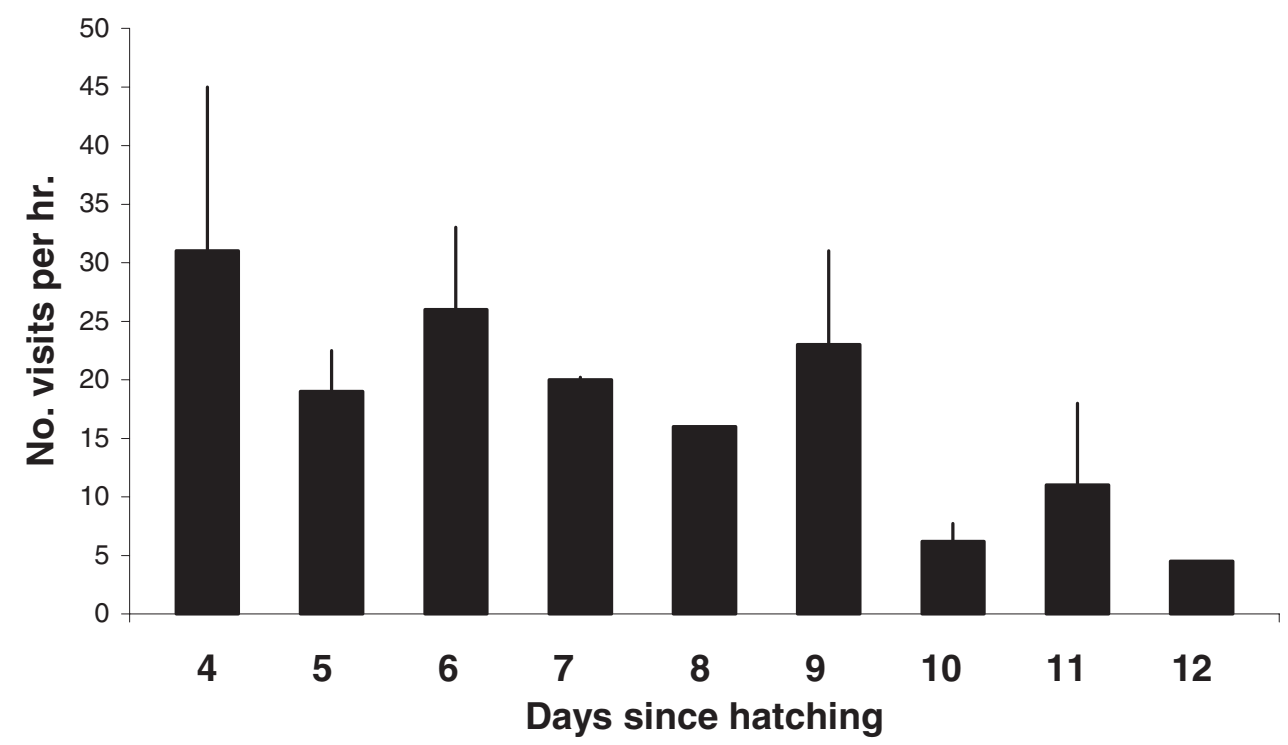

Figure 2. Brooding rate of nestling by a female Long-wattled Umbrellabird. Mean number of visits per hour \pm S.E. are shown. 
Table 1. Food items fed to nestling by a female Long-wattled Umbrellabird. We were unable to determine the identity of items regurgitated by the female.

\begin{tabular}{llccc}
\hline Food item & Sub-total & Number & Sub-total & Percentage \\
\hline Vertebrates & 12 & & 21.8 & \\
$\quad$ Lizard (Anolis sp.) & & 10 & & 18.2 \\
Frog & & 1 & & 1.8 \\
$\quad$ Snake & 1 & 58.2 & 1.8 \\
Invertebrates & 32 & & \\
$\quad$ Butterfly & & 10 & & 10.9 \\
Caterpillar & 2 & & 18.2 \\
Cicada & 3 & & 3.6 \\
Grasshopper & 1 & & 1.8 \\
Spider & & 5 & 9.1 \\
Walking stick & 5 & & 9.1 \\
$\quad$ Unknown insect & & & \\
Regurgitated items & 11 & 55 & & \\
Totals & & & & \\
\hline
\end{tabular}

(M. Tellkamp pers. comm.). The female may have flushed off the nest in response to the flashes and may have been unable or unwilling to return to the nest that night.

\section{Discussion}

\section{Conservation implications}

Long-wattled Umbrellabirds are a priority for conservation, as they are listed as globally Vulnerable and Endangered in Ecuador (BirdLife International 2000, Jahn and Mena Valenzuela 2002). The results of our study, while far from conclusive, provide some preliminary but interesting perspectives on the conservation of this species.

Long-wattled Umbrellabirds appear willing to nest in degraded habitats. The nest we monitored was located in forest that had been protected for 10 years and had a high proportion of Cyathea tree ferns relative to more degraded, surrounding areas (J. Lyons pers. comm.). However, this forest had been heavily logged 30 years before and still showed obvious signs of degradation such as low tree diversity, few mature trees, and a high proportion of pioneer tree species. The nest was roughly $1.2 \mathrm{~km}$ from primary forest, but less than $200 \mathrm{~m}$ from a major paved highway and from Sachatamia Lodge, where there was a high level of human activity. Further, the nest was located immediately above a trail that was used daily. Similarly, a "hypothetical" nest discussed by Berg (2000) was located in a cacao tree Theobroma cacao on a traditional farm, in relatively degraded habitat. Thus, it appears that Long-wattled Umbrellabirds may be somewhat tolerant of degraded habitat and human activity when selecting nest sites. However, it is important to note that Long-wattled Umbrellabirds may rely on mature forest for other needs, such as foraging areas or lek sites (Jahn et al. 1999, Jahn and Mena-Valenzuela 2002). Both Berg's (2000) hypothetical nest and the nest we report on here were in close proximity to mature forest, and the female we observed usually departed in the direction of the mature forest. 


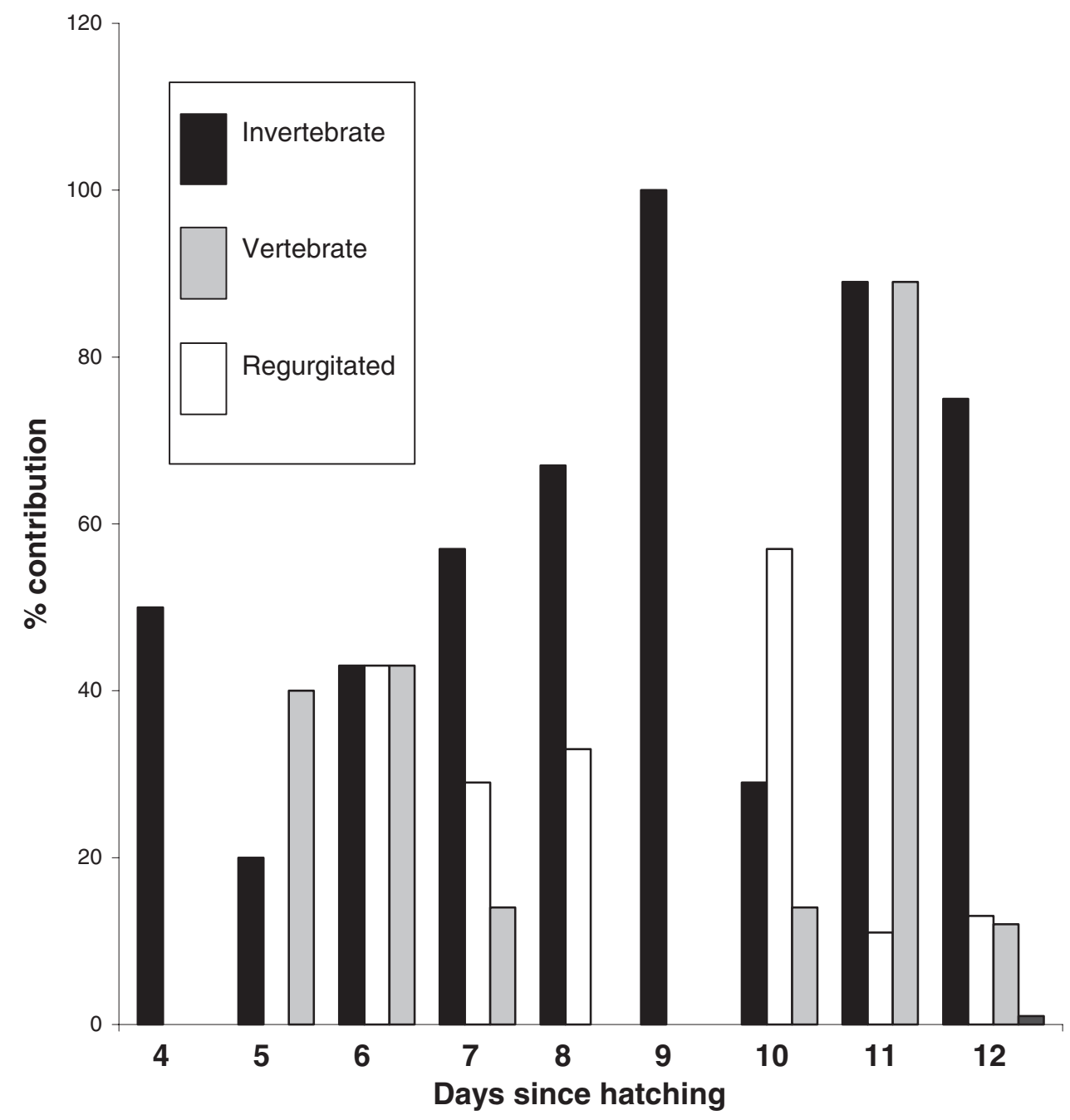

Figure 3. Food items (\%) fed to a nestling Long-wattled Umbrellabird in relation to nestling age.

Habitat loss and degradation is thought to be the greatest risk facing Longwattled Umbrellabirds (BirdLife International 2000, Jahn and Mena-Valenzuela 2002), and their willingness to nest at least sometimes in disturbed habitat could be seen as an encouraging sign for the species' preservation. However, nesting in degraded habitats and/or in close proximity to humans has been shown to lead to reduced reproductive success in many species (Robbins et al. 1989, Askins 1995, Faaborg et al. 1995, De Santo et al. 2002). In the case of Long-wattled Umbrellabirds, nesting in degraded habitat could lead to increased mortality and/or decreased nest success due to heightened risk of depredation, hunting, or risk of harassment from over-zealous birdwatchers (BirdLife International 2000). 


\section{General information}

There have been several unconfirmed accounts of nests of Long-wattled Umbrellabirds. The first two nests, described by Goodfellow (1902) and von Hagen (1938), are both probably erroneous as they were located in tree holes, a type of nest unreported for any other Cotingidae (Snow 1982). Berg (2000) reported three unconfirmed nests in the Bilsa Reserve, Esmeraldas province at an elevation of $400-700 \mathrm{~m}$. These nests were hypothetically active between February and April, which corresponds to the peak wet season in the humid premontane rainforest of Bilsa. One nest was located in secondary forest, roughly $50 \mathrm{~m}$ from a patch of primary forest of undetermined size. The nest, which was located $3.5 \mathrm{~m}$ above the ground, was constructed of long, thin twigs and was structurally similar to the nest we documented. This nest was considered as hypothetical by Berg (2000) because he was told that it was used by a Longwattled Umbrellabird, but it was inactive when he visited it.

The little information that exists on the foraging ecology of Long-wattled Umbrellabirds suggests that the prey items brought to the chick may differ from the diet of adults. Long-wattled Umbrellabirds appear to be primarily frugivorous when not feeding dependent young: the majority of foraging observations of the species in Bilsa ( $98 \% ; n=100$ total observations) were of fruit, with only two observations of insect prey and none of vertebrates (Berg 2000). In contrast, the prey items brought to the chick in our study were mainly invertebrates and vertebrates (Table 1). Even if we assume all regurgitated items were fruit, this only accounts for roughly $20 \%$ of the chick's diet.

It has been suggested that Long-wattled Umbrellabirds exhibit an "explodedlek" mating system, in which males aggregate in one general area and display to females with vocalizations, the wattle, and the crest (Snow 1982, Jahn et al. 1999). In typical lek mating systems, females are thought to visit the lek and assess male quality. After copulating with a reproductive partner, the females are solely responsible for all aspects of nesting biology (Andersson 1994). In keeping with these expectations, the female we observed did all incubation and feeding.

Cotingas inhabiting areas with unevenly distributed rainfall tend to breed towards the end of the dry season, presumably in order to take advantage of the greater abundance of insects and certain fruits during the ensuing wet season (Snow 1982). In Mindo, rainfall is highly seasonal, with the dry season extending from June to December (Instituto Nacional de Meteorología e Hidrología de Ecuador unpubl. data Jarrin 2001). The nest we monitored was active in June, and therefore coincided with the end of the wet season and the onset of the dry season. It is unclear whether the nest we monitored was unusually early in the breeding season, or whether timing of breeding by Long-wattled Umbrellabirds in the Mindo area does not conform to temporal patterns found in other Cotingas.

\section{Relation to congeners}

The nesting biology of Long-wattled Umbrellabird appears to be superficially similar to that of its two congeners, Amazonian Umbrellabird C. ornatus and 
Bare-necked Umbrellabird C. glabricollis, which replace it geographically to the east and north, respectively (Snow 1982). All three species lay a single egg and appear to select qualitatively similar nest sites (Sick 1954, Snow 1982, Fogden and Fogden 1997). Sick (1954) reported an Amazonian Umbrellabird nest $12 \mathrm{~m}$ above the ground in continuous forest. A Bare-necked Umbrellabird nest was situated $5 \mathrm{~m}$ above the ground in an isolated tree that had a dbh of $20 \mathrm{~cm}$. The tree in which the nest was situated had remnants of two other nests, suggesting that the female re-nested repeatedly in the same tree (Fogden and Fogden 1997). This nest also failed, due to the chick being predated at about 1o days after hatching.

\section{Acknowledgements}

We thank the Salazar family and Sacha Tamia staff for logistical support and for allowing us to work on their property. Karl S. Berg, Seb Buckton, Olaf Jahn, and Jane Lyons made comments that greatly improved the manuscript. We also thank Mercedes Rivadeneira (Neblina Forest) and Sandra Loor-Vela (CECIA) for loaning telescopes and logistical support, and Hugo Navarrete for identifying the tree fern. J. Karubian was supported by a post-doctoral fellowship from the National Science Foundation, IRCEB-0077072 to TBS and a Research Fellowship from the Wildlife Conservation Society.

\section{References}

Andersson, M. (1994) Sexual selection. Princeton, NJ: Princeton University Press.

Askins, R. A. (1995) Hostile landscapes and the decline of migratory songbirds: Science 267: 1956-1957

Berg, K. S. (2000) Field notes on the biology of the Long-wattled Umbrellabird Cephalopterus penduliger in west Ecuador. Cotinga 14: 26-29.

Birdlife International. (2000) Threatened birds of the world. Cambridge, U.K. and Barcelona: BirdLife International and Lynx Edicions.

Conservation International. (2001) Ecosystem profile: Chocó-Manabi conservation corridor of the Chocó-Darien-western Ecuador hotspot. Washington, D.C.: Conservation International.

Cracraft, J. and Prum, R. O. (1988) Patterns and processes of diversification: speciation and historical congruence in some Neotropical birds. Evolution 42: 603-620.

De Santo T. L., Willson M. E.; Sieving, K. E. and Armesto, J. J. (2002). Nesting biology of tapaculos (Rhinocryptidae) in fragmented south-temperate rainforests of Chile. Condor 104: 482-495.

Dinerstein, E., Olson, D. M., Graham, D. J., Webster, A. L., Primm, A., Bookbinder, M. P. and Ledec, G. (1995) A conservation assessment of the terrestrial regions of Latin America and the Carribbean. World Bank, D.C.: Washington.

Dodson, C. H. and Gentry, A. H. (1991) Biological extinction in western Ecuador. Ann. Miss. Bot. Gard. 78: 273-295.

Faaborg, J., Brittingham, M. C., Donovan, T. M. and Blake, J. (1995) Habitat fragmentation in the temperate zone. Pp. 357-380: In T.E. Martin and D.M. Finch, eds. Ecology and management of Neotropical migratory birds. New York: Oxford University Press.

Fogden, M. P. L. and Fogden, P. M. (1997) Notes on the behaviour of Bare-necked Umbrellabird Cephalopterus glabricollis in the Monteverde Cloud Forest Preserve, Costa Rica. Cotinga 8: 23-26. 
Goodfellow, W. (1901) Results of an ornithological journey through Colombia and Ecuador. Ibis 8: 300-319, 458-480, 699-715.

Hagen, W. von. (1938) On the capture of the Umbrella Bird (Cephalopterus penduliger Sclater). Proc. Zool. Soc. London 108: 27-30.

Jahn, O. and P. Mena-Valenzuela. (2002) Cephalopterus penduliger. Pp. 177-178 in T. Granizo, Pacheco, C., Ribadeneira, M. B., Guerrero, M. and Suarez, L., eds. Libro Rojo de las Aves del Ecuador. Quito, Ecuador: Simbioe, Conservacion Internacional, EcoCiencia, Ministerio del Ambiente and UICN.

Jahn, O., Vargas Grefa, E. E., and Schuchmann, K. L. (1999) The life history of the Longwattled Umbrellabird Cephalopterus penduliger in the Andean foothills of north-west Ecuador: leks, behaviour, ecology and conservation. Bird Conserv. Internatn. 9: 81-94.

Jarrín, V. P. (2001) Mamíferos en la Niebla: Otonga, un Bosque Nublado del Ecuador. Quito, Ecuador: Museo de Zoología, Centro de Biodiversidad y Ambiente, Pontificia Universidad Católica del Ecuador.

Ridgely, R. S. and Greenfield, P. J. (2001) The birds of Ecuador. Ithaca, NY: Cornell University Press.

Ridgely, R. S. and Tudor, G. (1994) The birds of South America, 2. Austin: University of Texas Press.

Robbins, C. S., Dawson, D. K. and Dowell, B. A. (1989) Habitat area requirements of breeding forest birds of the middle Atlantic states. Wildl. Monogr. 103: 1-34.

Salaman, P. G. W. (2001) The study of an understorey avifauna community in an Andean Premontane Pluvial Forest. D.Phil. thesis. University of Oxford, U.K.

Sick, H. (1954) Zur Biologie des amazonischen Schirmvogels, Cephalopterus ornatus. J. Orn. 95: 233-244.

Sierra, R. (1999) Vegetación remanente del Ecuador Continental. Circa 1996. 1:1,000,000. Quito, Ecuador: Proyecto INEFAN/GEF y Wildlife Conservation Society.

Snow, D. W. (1982) The cotingas: bellbirds, umbrellabirds and other species. London and Ithaca, NY: British Museum of Natural History and Cornell University Press.

Stattersfield, A. J., Crosby, M. J., Long, A. J. and Wege, D. C. (1998) Endemic Bird Areas of the world: priorities for biodiversity conservation. Cambridge, U.K.: BirdLife International.

JORDAN KARUBIAN ${ }^{1}$ and THOMAS B. SMITH

Center for Tropical Research, Institute of the Environment, University of California at Los Angeles, 610 Charles E. Young Drive South, Box 951496, Los Angeles, CA 90095-1496, U.S.A. E-mail: jordank@ucla.edu

GABRIELA CASTAÑEDA, JUAN F. FREILE and TATIANA SANTANDER

Center for Tropical Research, Guanguiltagua N3857, Batán Alto, Quito, Ecuador.

RAMIRO T. SALAZAR

Sachatamia Lodge, Av. González Suárez 432, Dpto \#9o1, Quito, Ecuador.

${ }^{1}$ Author to whom correspondence should be sent.

Received 20 September 2002; revision accepted 19 May 2003 